\title{
On the Artistic Value of Literary Ekphrasis
}

\author{
Zhangfan Shangguan", Dong Wang \\ School of Liberal Arts, Nanjing University of Information Science and Technology, Nanjing 210044, Jiangsu, China \\ Email: 20191246005@nuist.edu.cn
}

\begin{abstract}
As a language attribute that exists for visual arts, ekphrasis is not only a bridge to communicate poetry and painting, but also an important category in the cross-media and cross-disciplinary research of literature and art. Through the process of recreating paintings by using language as a medium, ekphrasis realizes the conversion from visual art to auditory art, and explores the richness of cognitive creation on the basis of the reproduction of visual art. In this process, the literary narrative diagram shows significant differences from the artistic doctrinal diagram, which are mainly reflected in the three levels of academic guiding ideology, narrative style difference and classic deconstruction and reconstruction. In addition, literary storytelling plays an important role in the writing of art history and the dissemination of artworks. It provides reference and inspiration for the current cross-border and in-depth integration of literature and art from the perspective of practical creation.
\end{abstract}

Keywords: literary ekphrasis, art history, value, communication

Ekphrasis has become a hot word in academic research in the current multimedia era. Broadly speaking, it is a common term involving many fields such as literature, aesthetics, and art. From a narrow perspective, academic research in the Western academic circles generally defines it as "the literal description of real or imagined visual art" or "the literal representation of visual representation". The research category of "ekphrasis" includes not only the comment, analysis or evaluation of paintings, but also the discourse of paintings placed in the context defined by other literary and artistic works. In short, ekphrasis is a verbal description of painting, that is, there are paintings, descriptions and language media. These elements are interconnected, and behind it is a broad social and cultural context. As a result, with the deepening of the study of ekphrasis, the concept of ekphrasis also extends to music, movies, etc. It may serve for artistic argumentation, often used in the interpretation of painting works, art history writing description; or as the expression of inner emotions, narrative pictures, and usually appear in the form of poetry, novels, prose, etc.

\section{The difference between literary ekphrasis and artistic ekphrasis}

Compared with the literary ekphrasis and the artistic ekphrasis, the differences are mainly reflected in the following three aspects.

\subsection{Academic thought}

Since the day of its birth, the main presentation methods of artistic ekphrasis are art history writing and painting aesthetics commentary. Its purpose is mainly to serve art argumentation. It basically depends on the circle of commentary activities or art history, and it is less imaginative. Sexual and emotional fiction, emphasizing objectivity and accuracy. The literary ekphrasis emphasizes the description of visual arts such as painting by literature, which is different from the description of visual arts by art history and art criticism. The language of literature on painting involves the characteristics and differences of the two media, and highlights the autonomy, creativity, and literary nature of literature. It is not only different from picturism, but also different from classical picturism - - The imitation and reproduction of visual art content in classical literature. Literary ekphrasis's academic thinking is to emphasize self-creative description, aiming to achieve a certain vividness or visuality, which inevitably requires a breakthrough in language and expression. Literary ekphrasis attempts to break through the media boundary of language to achieve the spatial visual effect of painting.

\subsection{Narrative style}

Art history is a history of images, but also a history of images being told and written. The article "As a Modeling Description of Art History" published in 2010 systematically explored the decisive role of language description in the writing of art history. Although the history of art works has its continuity in time and inheritance in technique, art history is undoubtedly and without exception, and must be written in language. The narrative focus of literary narrative pictures is different from that of artistic narrative pictures. Literary narrative pictures are more concerned with a kind of linguistic and 
literary phenomenon, the clues of time context are relatively thin, and more are the horizontal narration and narration of a certain work. Involving cross-media, semiotics or structuralism, etc. Of course, literary ekphrasis will also use the narrative works of a certain period of time as a clue to discuss, but the key point is to summarize the artistic expression of literature in this era and discuss the differences between different symbols, mostly from the level of theory or literary criticism. Unfold.

\title{
1.3 Classic definition
}

Artistic description of pictures refers to the objective image reproduction of an actual work of art, and language expression emphasizes explanatory and objectivity. What the text depicts is not an objectively existing natural object, but as a recurring visual art. In addition, one of the important characteristics of Art ekphrasis is that its interpretation only focuses on the artistic work, emphasizing its composition, color, light and other painting elements. Therefore, the classics of art descriptions are the classics of art painting. The reason why these paintings, fine arts and other works are wellknown is that people study and explain their brushwork, colors, and composition. His classic works also revolve around the exposition and explanation of real paintings, that is, act ekphrasis. Literary descriptions include the creation of a writer and the description of an imaginary artwork or a literary description of an objectively existing painting. His classic works belong to the notional ekphrasis from the way of presentation.

\section{The function of literary storytelling in writing art history}

Literary narrative diagrams and artistic narrative diagrams are not completely distinct in the history of development. Ekphrasis really used a literary method as a way of writing art history gradually appeared in the second century AD. For the same painting, Art ekphrasis introduces the line, composition, color, contrast, etc. from the perspective of the art discipline, and also involves the background introduction of its art category and art genre. Literary Speaking Pictures interprets images through a series of processes of viewing, recognizing, and resolving pictures, which is imaginative and emotional. Literary ekphrasis uses temporal attributes to complete the narrative logic, focusing on narrating the sense of time and space not involved in art history in painting.

The time and space of poetry does not refer to the content of time and space depicted in the poem, but the method and form used by the poet in the description process. For example, in "Introduction to Space Poetics", Chen Zhenlian attributed the course of song from tradition to modernity as the course of poetry from hearing to vision, from time to space. From another point of view, the explanatory and objectivity of the art description picture is narrative and descriptive in terms of form, and it is undoubtedly a kind of sequential auditory art. However, the literary description of pictures presents more imagery, non-sequential, and spatial images, and there are no fixed rules for emotional fiction. The poem "Portrait of a Lady" (Portrait of a Lady) by William Carlos Williams:

\author{
Your things are appletrees \\ whose blossoms touch the sky. \\ Which sky? The sky \\ where Watteau hung a lady's \\ slipper. Your knees \\ are a southern breeze - or \\ a gust of snow. Agh! What \\ sort of man was Fragonard? \\ - As if that answered \\ anyhing. Ah, yes - below \\ the knees, since the tune \\ Drops that way, it is \\ one of those white summer days, \\ the tall grass of your ankles \\ flickers upon the shore - \\ Which shore? \\ the sand clings to my lips - \\ Which shore? \\ Agh, petals maybe, How \\ should I know?
}


Which shore? Which shore?

I said petals from an appletree.

This poem by Williams is based on the position of the third character, a voyeur hiding in the grass. The content of the poem suddenly appears to be a dialogue-a dialogue between the voyeur and the stolen, but it can also be regarded as a dialogue designed by the voyeur himself in his mind-an "inner monologue" in the form of a dialogue. In order to express the excitement, tension and anxiety of the voyeur under the fierce collision of social morality and voyeuristic desire, Williams used brainstorming and montage techniques to superimpose some seemingly unrelated and fragmented images together. For example: apple trees, sky, slippers, weeds, beaches and petals, etc., set off the frivolous and vulgar beauty of the lady. She deliberately threw out her shoes and spread her legs to flirt with the young man. The young man stared at the woman on the swing eagerly and fanatically, implying the vulgar artistic taste of the aristocracy at that time. It coincides with the dreamy colors displayed by Fragonard through superb light, shadow and color techniques in the original paintings, and truly reproduces the life of the French aristocracy in the 18th century. The hedonism shown in the poems is superior to the paintings, and it fully expresses the flirting sketches between gentlemen and ladies in this era.

It can be seen that literary descriptions and pictures also play a pivotal role in the writing of art history. As Heffernan concluded: If there is no picture, the history of art cannot be told. Art history requires the interpretation, imagination, and social and cultural background of literary ekphrasis. It is this new approach that makes art history more mature and rich, and ekphrasis also develops and perfects itself in this process. As Mitchell mentioned, art history, as the language representation of visual representation, is a vision that elevates the description of pictures to the dialogue of disciplines. Art history began to shift to broader visual studies or image studies during this period.

\section{The role of literary storytelling in the dissemination of art}

The end of the 18th century was an unusual era. Artists and writers in Paris desperately wanted to exchange ideas with each other. The balance of artistic influence has undergone a subtle shift, and visual artists have begun to get rid of the dictatorship of literature and historical narrative. The struggles of some painters and the hard-won freedom touched many writers, and they were attracted by the new ways of viewing by these painters. Henry James admitted: "What language artists want to do is to find the secrets of image art and drink the water of the same origin." Literary critics and critics have also become the main force of art dissemination.

\subsection{Literature has opened up a new paradigm for the dissemination of art}

At the end of the 18th century and the beginning of the 19th century, with the collapse of the monarchy and the decline of the aristocracy, the bourgeoisie rose. Their economic success has prompted their lifestyles to follow the traditional aristocratic class: paying attention to art, moving luxury goods into the premises to decorate the facade, and striving to create a family art atmosphere to enhance their identity... However, traditional academic creation still occupies painting Half of the historical stage, the formation of a new market is an opportunity and a challenge for ordinary painters. Some painters who have difficulty selling their paintings cannot make a living. In the true sense, these people are not recognized by the society as professional painters. For these avant-garde artists, integrating into the painting market has become an important topic, and poets, critics, and art dealers have played an important role in this process. Art dealers actively bought these paintings, provided support for Impressionist exhibitions and solo exhibitions, and sold their works to collectors in the United States and Europe. Critics and poets who supported paintings with pens used their own creations and fame to create momentum for these paintings. Unofficial exhibitions have gradually emerged, and private collections have gradually begun to be opened to the public. The personal exhibitions of painters and collectors directly promoted the speed of the commercialization of art in the 19th century. The consumption and sponsorship of art broke the rule of the monarchs, nobles, and nobles. The state's monopoly on art has become an emerging sponsorship force. As explained in the "History of Western Painting": "If there were no poet critics such as Charles Baudellinaire in the Romantic era and Guillaume Apollinaire in the Cubism era, the art dealers who now provided support for the Impressionists Paul Durandruel, the painter and critic Daniel-Henry Kahnweiler and others, presumably modern art history will be quite lonely".

Philosophy and aesthetics not only refreshed the aesthetic concept of artists, but also changed the form of expression of artistic works. As a literary method, picture-telling was quite popular in the creation of this period. Romantic poets such as Keats, Byron, Wordsworth and other romantic poets re-created poems based on paintings became classics, which were more confirmed in the process of promoting the development of painting. In order to realize its artistic potential, the framework of the "art dealer and critic system" was established from the "academic system" based on the official art system. As a new type of poetry, ekphrasis greatly promoted the promotion and development of painting at that time, From 
the perspective of poets and critics, opened up a new paradigm for the dissemination of paintings and other artworks.

\subsection{Literature creates a sense of sacred space in art}

The gathering of writers, critics, painters, and collectors, coupled with the fact that some artists have multiple identities, has greatly promoted the prosperity and development of art. Take Proust as an example, watching, listening, and studying in towns. He knows many painters and discusses their works with them in private residences. He also knows art critics and reads critical articles. He participated in exhibitions and visited galleries. Du Weien's son-in-law, art collector and dealer Rene Gimpel, who owns twelve Rembrandt works, are his friends; publisher, Gazette Charles Ephraussi, editorin-chief of des Beaux-Arts, authorized Proust to consult the rich library of the magazine's library by himself, where he carefully read the informative Burlington Magazine (Burlington Magazine). Magazine), browsed the auction catalog. These interactions have made many artworks that have been submerged in the historical panning or hard to see their true faces have been reproduced in the narrative works of writers such as Proust, establishing "absence of presence and sacred space" - Through the presence of literary narrative, it creates a sense of mystery for artworks.

On the one hand, the dissemination of art works by talking pictures is to establish an absent sense of sacred space. As a kind of artistic writing method that evokes readers' visual imagination, ekphrasis pursues a lifelike description of visual artworks, so that even if the audience does not witness the art in practice, they can form a "mental image" through language description, thereby achieving The effect of "watching" and dissemination. In the era of digital media, the illusory effects and immersive experience brought by computer virtual family members have also profoundly changed the process of visual objects from production, dissemination to reception. On the other hand, the interactive experience can increase the audience's expectations of the original painting. ekphrasis uses text to describe the process of constructing mental images, enabling the audience to experience the successive creative process. However, paintings and other artworks emphasize capturing a certain moment in the ever-changing nature, which requires the juxtaposition of scenes in the reading of the audience's language and text, and ultimately the difference between the scene constructed through the description of the picture and the real painting can be more exciting The audience's desire and exploration for real artworks. In the current era of globalized dissemination of audiovisual products, images can continue to migrate in cross-cultural vision, and the consumption of mass media greatly affects the way people receive language, images, and visual events. Saying pictures will make it possible to make the "seeing" visible, challenging the cultural tradition of "seeing", and thus promote the dissemination of art.

\section{The enlightenment of literary storytelling on artistic innovation}

The purpose of art narration is to serve art argumentation. The purpose of literary narration is to break through the media limitations of language to achieve artistic reproduction, thereby realizing the re-creation of literature. Although the two belong to different disciplines, they are generally based on Visual art, or more or less dependent on the painting or the image itself, can be said to be two parallel rivers, developing and advancing according to their own trajectory. In the current new era of interdisciplinary and fusion of disciplines, the two sides are also exploring new vitality. As a way of artistic writing, literary storytelling is extremely creative. The vivid and connotative artistic writing has had a powerful impact on the traditional hard and rigid artistic writing. In addition, the imagination and emotion behind the language description have become an important feature of artistic writing. As Mr. Zhao Xianzhang pointed out, the decisive role of language in art history is also determined by the forms of these two different sign media: "Language is a sign of materiality, and an image is a sign of imaginary sign. It is the materiality of language. , Determines its credibility." This shows that art history is not only a history of images, but also a history of writing language images that exist in a specific way. On the other hand, the diversification of contemporary art media and art symbols puts forward more urgent requirements for the cross-media research of ekphrasis. For the description of imitative painting, abstract painting or performance art, different rules and attitudes will be followed, and new concepts and terms will continue to be formed. As a result, the theory of literature is evolving into a research methodology of art, enabling people to discuss the development and evolution of art history through writing of art history. On the other hand, the "absence of sacred space" established by literature in works also has a profound impact on the current art dissemination.

\section{Acknowledgments}

This work was supported by the General Project of the National Social Science Foundation (No. 15BZW037) and the Postgraduate Research \& Practice Innovation Program of Jiangsu Province (No. KYCX20_0944). 


\section{References}

[1] Mario Klarer. Ekphrasis. Routledge Encycllopedia of Narrative Theory. Ed. David Herman, Manfred Jahn, Marie-Laure Ryan. New York: Routledge; 2005.

[2] Maria Rubins. Crossroad of Arts, Crossroad of Culture: Ekphrasis in Russian and French Poety. New York: Multimodality and Intermediality.

[3] Li Jian. On "Artistic Words" as a Cross-Media Discourse Practice. Literature and Art Research. 2019; (2): 42

[4] Wang Dong. Research on "ekphrasis" as a subject category of art. Xinjiang Art Journal. 2016; (12): 83.

[5] Erwin Panofsky, Jas Elsner, Katharina Lorenz. On the Problem of Describing and Interpreting Works of the Visual Arts. Critical Inquiry. 2012; 38: 468.

[6] Li Xiao. Description and Interpretation Tradition in Western Art History. Shanghai University; 2018.

[7] Raymond A. Macdonald. Ekphrasis, Paradigm Shift, and Revisionism in Art History. Anthropology and Aesthetics. $1993 ; 24: 112-123$.

[8] Li Hong. Vasari's "Artistic Style" and its traditional origin in "The Biography of Famous People". New Art. 2003; (3): 39.

[9] Keats. Keats Poems, Translated by Tu An. Beijing: People's Literature Publishing House; 1997.

[10] Li Xiao. The history and function of Yige's poems. Journal of China Academy of Art. 2018; (1): 55.

[11] Wang Yong. The Art of Time and Space in the Poetry of William Carlos Williams. Papers of the International Symposium on American Poetry in the 20th Century in Wuhan, Hubei, China

[12] Chen Zhenlian. Introduction to Space Poetics. Shanghai: Shanghai Literature and Art Publishing House; 1989.

[13] Takahashi Yuko. History of Western Painting. Beijing: CITIC Publishing Group; 2017.

[14] WILliAM W C. The Collected Earlier Poems of Willian Cardos Williams. New York: New Direcitions Press; 1938.

[15] James Heffernan. Cultivating Picturacy: Visual Art and Verbal Interventions. Waco, Texas: Baylor University Press; 2006.

[16] See Norman Bryson, Michael Ann Holly, Keith Moxey (eds). Visual Culture: Image and Interpretations. Hanover \& London: Wesleyan University Press; 1994.

[17] Derrida. A crazy guardian thought: Interview with Derrida. He Peiqun, translated. Bao Yaming, proofreading. Shanghai: Shanghai People's Publishing House; 1997.

[18] Zhao Xianzhang. The homeopathic and contrarianism of the mutual imitation of language pictures-A new theory of the relationship between literature and image. Chinese Social Sciences. 2011; (3). 